The final publication is available at

http://dx.doi.org/10.1016/j.socec.2015.01.006

\title{
Think Twice Before Running! Bank Runs and Cognitive Abilities
}

\author{
Kiss, H. J. * Rodriguez-Lara, I. ${ }^{\dagger} \quad$ Rosa-García, A. ${ }^{\ddagger}$
}

January 28, 2015

\begin{abstract}
We assess the effect of cognitive abilities on withdrawal decisions in a bank-run game. In our setup, depositors choose sequentially between withdrawing or keeping their funds deposited in a common bank. Depositors may observe previous decisions depending on the information structure. Theoretically, the last depositor in the sequence of decisions has a dominant strategy and should always keep the funds deposited, regardless of what she observes (if anything). Recognizing the dominant strategy, however, is not always straightforward. If there exists strategic uncertainty (e.g., if the last depositor has no information regarding the decisions of predecessors), then the identification of the dominant strategy is more difficult than in a situation with no strategic uncertainty (e.g., the last depositor is informed about all previous decisions). We find that cognitive abilities, as measured by the Cognitive Reflection Test (CRT), predict withdrawals in the presence of strategic uncertainty (participants with stronger abilities tend to identify the dominant strategy more easily) but that the CRT does not predict behavior when strategic uncertainty is absent.
\end{abstract}

Keywords: bank runs, coordination game, observability of actions, cognitive abilities, strategic uncertainty

JEL Class.: C91, D03, D8, G02, J16

*Eötvös Loránd University - Department of Economics, 1117 Budapest, Pázmány Péter sétány 1/a, Hungary. Email: hubert.kiss@tatk.elte.hu. Also a research fellow in the Momentum (LD-004/2010) Game Theory Research Group at the MTA KRTK

${ }^{\dagger}$ Middlesex University London. Business School, Hendon Campus, The Burroughs, London NW4 4BT, UK. Email: I.Rodriguez-Lara@mdx.ac.uk and Research Fellow at LUISS Guido Carli University, Rome (Italy)

${ }^{\ddagger}$ Facultad de Ciencias Juridicas y de la Empresa, Universidad Catolica San Antonio. Campus de Los Jeronimos, s/n, Guadalupe 30107, Murcia, Spain. Email: arosa@ucam.edu 


\section{Introduction}

"If the people would only leave their money in the banks instead of withdrawing it...everything would work out all right.»

J. P. Morgan in "Bankers Calm; Sky Clearing."

New York Times, October 26, 1907.

Standard economic theory assumes that agents are rational and make optimal decisions. However, laboratory experiments emphasize that participants frequently undertake suboptimal decisions. This real-life phenomenon can have noteworthy economic consequences. The events in the US housing market that fostered the recent economic downturn, for example, were likely to be partly caused by poor financial decision making (see Gerardi et al., 2013). Poor decisions are also made in other financial environments. Choi et al. (2011) find that some employees forgo arbitrage profits by making suboptimal investment choices to retirement plans (see also van Rooij et al., 2011). Bertrand and Morse (2011) note that some individuals may not be aware of the real costs of a loan from payday lenders, which may induce them to take out extremely expensive loans (even when information about alternative ways of obtaining money is easily available).

Because poor financial decisions may lead to severe economic losses, it is instructive to understand what factors may cause them. A straightforward answer to consider is that individuals are not as rational as assumed in standard economic theory. Individuals may have not the necessary cognitive abilities to overcome potentially complex financial problems or they may act impulsively without appropriate deliberation. There is a growing body of literature studying how cognitive abilities affect financial decision making (see Korniotis and Kumar 2010 for a survey). In this paper, we contribute to this literature by conducting a lab experiment to study participants' decisions in a bank-run game (see Kiss et al. 2014a, 2014b). As suggested by the opening sentence of J. P. Morgan, bank runs involve decisions in a situation in which choosing an action (in this case, withdrawing money from the bank) may be in conflict with the rationality assumption; thus, this scenario is suitable for analyzing the extent to which participants behave rationally.

We follow Diamond and Dybvig (1983) and model bank runs as a coordination problem among depositors. In our game, there is an impatient de- 
positor who always withdraws money from the bank due to liquidity needs, and two patient depositors who must choose whether to withdraw their funds from the bank or keep them deposited (which we also call waiting). In our experiment, the impatient depositor is simulated by the computer, while the patient depositors are the participants in the experiment. The depositors decide based on various information sets that differ in the participants' position in the sequence of decision and the available information (both about previous depositors' decision and whether subsequent depositors will observe the decision of the participant). Payoffs are such that both patient depositors receive the highest possible payoff if both of them wait. Moreover, keeping the money deposited is the dominant strategy for a patient depositor choosing in the last position, regardless of what is observed (if anything). However, strategic uncertainty (that is, lacking information about the decision of the other patient depositor) makes the decision more difficult in our setup for at least two reasons. First, the computation of payoffs is easier when a patient depositor knows with certainty what the other participant in the lab did. For instance, when a depositor in the last position observes all the previous decisions or knows that a previous depositor has already decided to keep the money in the bank, she decides in a singleton information set. Comparing payoffs corresponding to the choices reveals that keeping the money deposited is optimal. However, when a depositor in the last position observes a withdrawal or none of the previous choices, the computation of payoff is not immediate. Keeping the money deposited is still a dominant strategy but it requires more complex thinking, in contrast with the straightforward comparison of payoffs in the previous case. The reason is that the depositor must think about all possible histories of decisions and must conclude that keeping the money deposited is the dominant strategy. Second, related to the previous point, strategic uncertainty also implies payoff uncertainty. Because the payoff for a depositor in the last position depends on what other depositors have chosen, a depositor who observes nothing is uncertain about the payoff that her action yields, and this uncertainty may cause some stress and therefore suboptimal decision-making. ${ }^{1}$

We use data from a previous experiment (Kiss et al. 2014b) to inves-

\footnotetext{
${ }^{1}$ Risk preferences are indeed correlated with different measures of cognitive abilities, as shown by Andersson et al. (2013), Brañas-Garza et al. (2008), Burks et al. (2009), Dohmen et al. (2010) and Oechssler et al. (2009).
} 
tigate the behavior of depositors when the available information changes from round to round. We focus on the behavior of the last depositor in the sequence because suboptimal behavior is clearly defined in that setting. To measure cognitive abilities we use the Cognitive Reflection Test (hereafter, CRT) devised by Frederick (2005). All three questions in the test have an answer that immediately comes to mind, although the answer is wrong. The test is then intended to measure the tendency "to resist reporting the response that first comes to mind"; thus it may have some predictive power in depositors' behavior, as it is not only about intelligence but also about impulsiveness. ${ }^{2}$ Given our experimental environment, we seek to test whether participants really play the dominant strategy. Moreover, we attempt to understand what may underlie the mistake of playing the dominated strategy. We conjecture that strategic uncertainty and cognitive abilities are the two main driving forces behind suboptimal decisions. More precisely, we expect that i) participants with higher cognitive abilities (as measured by the CRT) make fewer mistakes, and ii) strategic uncertainty (i.e., information about predecessors' actions) increases the likelihood of suboptimal choices. We also attempt to investigate the relationship between cognitive abilities and strategic uncertainty.

Our data show that participants tend to recognize the dominant strategy and withdraw in only 10 percent of the cases. Interestingly, we find that they incur more mistakes when there is strategic uncertainty. In this case, however, participants with higher cognitive abilities withdraw significantly less often. This finding is not applicable when there is no strategic uncertainty, as the CRT does not have any predictive power in that case.

The remainder of the paper is structured as follows. In section 2 , we briefly review the literature. Section 3 presents the bank-run game that we use in the experiment, which is also discussed in section 3 . The experimental results are presented in section 4 . Section 5 concludes the paper.

\footnotetext{
${ }^{2}$ As noted by Bosch-Domènech et al. (2014) "What makes the CRT different from problem-solving or math tests is that the latter tests do not usually trigger a plausible intuitive response that must be overridden." (page 2). See also Kahneman (2011) for the relationship between the CRT and "lazy" thinking.
} 


\section{$2 \quad$ Related Literature}

Our paper is related to two strands of the literature. First, this study is connected to papers that investigate how cognitive abilities affect optimal decisions and economic behavior in general. Second, this research belongs to the body of work examining financial mistakes and analyzing its causes.

Related to the first branch of the literature, a noteworthy aspect of our study is that there is a dominant strategy that participants should play if they are rational. It has been long observed, however, that experimental participants do not always choose as theory predicts. Recently, several papers attempt to explain this discordance with cognitive abilities. These studies connect individuals' cognitive abilities, as measured by standard tests, with performance in different games. Casari et al. (2007) study auctions and find that individuals with higher scores on the Scholastic Achievement Test (SAT) or the American College Test (ACT) avoid the winner's curse more often than those with lower scores. ${ }^{3}$ It has also been observed that cognitive abilities affect the degree of strategic sophistication in the Hit-15 game (Carpenter et al., 2013); in games that require the application of iterated dominance, such as the beauty context (Brañas-Garza et al., 2012; Carpenter et al., 2013; Gill and Prowse, 2014; Rydval et al., 2009); and in some two-person $3 \times 3$ normal form games (Grimm and Mengel, 2012). ${ }^{4}$ Cognitive abilities also have an important role in behavioral economics, as they are correlated with behavioral biases such as anchoring (Bergman et al, 2010) or the conjunction fallacy (Oechssler et al, 2009). We depart from these studies in that we investigate the effect of cognitive abilities on the choice of a dominant strategy in the context of financial decisions in which subjects make their decisions sequentially, i.e., we allow for observability of actions in our experiment.

\footnotetext{
${ }^{3}$ Both the SAT and the ACT attempt to capture academic achievement. Originally, SAT was an abbreviation for Scholastic Aptitude Test, but SAT does not currently denote a sequence of words.

${ }^{4}$ Grimm and Mengel (2012) investigate learning and whether play converges to Nash equilibrium, and they find that the complexity of the environment affects convergence and the failure to converge is attributed to higher cognitive costs (see also Baghestanian and Frey (2014) for the relationship between strategic skills and Nash behavior). For further studies on the relationship between cognitive abilities and strategic behavior, see Allred et al. (2014), Bayer and Renou (2012), Benito-Ostolaza et al. (2015), Brañas-Garza et al. (2011, 2012), Burks et al. (2009) and Jones (2008, 2014), among others.
} 
Related to the second strand of the literature, there is a recent but rapidly growing body of literature on cognitive abilities and financial decisions (see Korniotis and Kumar (2010) for a survey of this topic). These papers show that cognitive abilities correlate with bubbles (Corgnet et al., 2014), savings (Ballinger et al., 2011) and consumption or investment decisions (Insler et al., 2015). Greater participation in the stock market (which is frequently used as a proxy for the quality of financial decisions) has been found to be positively related to IQ scores (Christelis et al., 2010; Benjamin et al., 2013). Other papers extend this research and use more specific measures of decision making. For instance, Grinblatt et al. (2012) and Korniotis and Kumar (2013) use different data sets and find that the portfolios of investors with high cognitive abilities perform significantly better in various aspects (e.g. stock-picking, trade execution) than the portfolios of investors with low abilities. In some studies, suboptimal decision-making is even more clearly defined. For example, Agarwal and Mazumder (2013) identify two instances (one related to credit card use and the other related to home equity loan application) in which suboptimal decisions lead to clear financial losses. The authors find that consumers with higher overall test scores, specifically those with higher math scores, are substantially less likely to make a financial mistake. ${ }^{5}$ Gerardi et al. (2013) find that cognitive ability (more precisely numerical ability) affects mortgage defaults; individuals with lower numerical ability are more likely to default on their mortgages.

Our setup resembles depositor behavior, an important type of financial decision making not covered in previous studies. We use the CRT to predict the depositor's behavior, as the correct answer to these questions can be found only by engaging in some cognitive reflection (see Kahneman, 2011). Toplak et al. (2011) convincingly argue that while CRT is correlated with standard cognitive ability measures (e.g. intelligence tests) it also captures important aspects of rational thinking that those tests fail to measure. More precisely, these researchers claim that CRT grasps the ability to override an initially primed incorrect answer and replace it with the correct answer. During financial hardship, people often panic and are driven by impulsive acts; therefore, this test seems appropriate to capture several of the aspects underlying suboptimal decisions. In light of the bank runs that have oc-

\footnotetext{
${ }^{5}$ In this study, cognitive skills were measured by the Armed Forces Qualifying Test (AFQT) score, which contains information on both math and verbal ability.
} 
curred since the financial crisis erupted, it seems of primary importance to understand how cognitive abilities may affect bank runs.

\section{The sequential bank-run game}

The seminal paper of Diamond and Dybvig (1983) models bank runs as a coordination problem among depositors. In their framework, decisions are made simultaneously and depositors may decide to run the bank as an equilibrium outcome. Recently, sequential decisions have received some attention in the literature on bank runs (e.g., Gu, 2011; Kinateder and Kiss, 2014). The experimental evidence emphasizes that observing the actions of other depositors may affect depositors' behavior (e.g., Garratt and Keister, 2009) even if decisions in the simultaneous and sequential setup should not differ (Schotter and Yorulmazer, 2009; Kiss et al., 2014a). These results are consistent with empirical studies that reveal the importance of observing previous decisions (e.g., Kelly and O Grada, 2000; Starr and Yilmaz, 2007; Iyer and Puri, 2012), and call for an extension of the simultaneous-move setup in Diamond and Dybvig (1983). In section 3.1 we build upon this foundation and present a simple coordination game among three depositors, which we implement in the lab by allowing for observability of actions (see Kiss et al. 2012, 2014a). As explained in section 3.2, our game has a straightforward prediction: the last depositor in the sequence of decisions (hereafter, depositor 3) has a dominant strategy. This dominant strategy may or may not be easy to identify, depending on what depositor 3 observes. We conjecture in section 3.2 that cognitive abilities and strategic uncertainty may have some predictive power in explaining departures from the equilibrium prediction.In section 3.3, we detail the procedure that we used to elicit risk aversion.

\subsection{The setup}

Two sessions were run at the LINEEX (University of Valencia) in June 2013 using the z-Tree software (Fischbacher, 2007). A total of 60 participants who had no previous experience in experiments with coordination problems or financial decisions were recruited from the undergraduate population of the university. All participants in the experiment were Economics or Business students. 
The experiment consisted of a total of 15 rounds following 3 trial rounds to become familiar with the software. ${ }^{6}$ At the beginning of each round, each participant was informed that she had been randomly matched to another participant in the lab and a third depositor (simulated by the computer) to form a three-depositor bank.

Each of the rounds has three periods $t=\{0,1,2\}$. In $t=0$, the participants deposit their initial endowment (in our experiment, 80 ECUs) in the bank, which initially has 240 ECUs to be invested in a project. The project yields a certain high return at the end of the round $(t=2)$ but the investment could be liquidated without any cost at $t=1$, yielding no net return.

At $t=1$, the depositors had to choose in an exogenously determined sequence whether they wanted to withdraw their initial endowment or keep it deposited. Depositor $i$ is the one who chooses in position $i$, where $i=1,2,3$. If a depositor decides to withdraw, then she immediately receives 100 ECUs as long as there is sufficient money in the bank to pay this amount (of this amount, 80 ECUs correspond to the initial endowment and 20 ECUs are obtained in the form of interest). In our experiment, if depositors 1 or 2 withdraw, then each of them receives 100 ECUs with certainty. However, if depositor 3 decides to withdraw after two withdrawals, then she receives only 40 ECUs (because the first two depositors who withdrew received 100 ECUs each, leaving only 40 ECUs in the bank to pay her). However, if depositor 3 withdraws after only one or no withdrawal, then the bank pays her 100 ECUs. In sum, if one or two depositors decide to withdraw at $t=1$, then they receive 100 ECUs. If all three depositors choose to withdraw, then the first two in line receive 100 ECUs each, and the last depositor receives the remaining 40 ECUs.

Depositors who decide to wait receive their payoff at the end of the round $(t=2)$. The amount that depositors receive in $t=2$ depends on the total number of waitings, which determines the amount of money that the bank has at $t=2$. If only one depositor waits, then she receives 60 ECUs. ${ }^{7}$ If two depositors wait, then each of them receives 140 ECUs. In our model, we assume that the three depositors cannot wait and keep the

\footnotetext{
${ }^{6}$ Appendix A contains the instructions. For a more detailed description of the game we refer interested readers to Kiss et al. (2014a, 2014b).

${ }^{7}$ After two withdrawals 40 ECUs remain in the bank at the end of $t=1$ and this amount earns 20 ECUs of interest until $t=2$.
} 
money deposited in the bank. In particular, the depositor simulated by the computer is hit by a liquidity shock at $t=1$ and is forced to withdraw. In line with Diamond and Dybvig (1983), there exists no aggregate uncertainty regarding the fundamental liquidity demand (i.e., it is commonly known that the computer is programmed to always withdraw). Following the literature, we refer to this depositor as the impatient depositor, whereas depositors who can wait or withdraw their money are called patient depositors.

The decision situation in our study is such that it pays off for patient depositors to wait if they know or believe that the other patient depositor is also waiting. Our setup, however, differs from standard coordination games in that it allows for the observability of actions, which is an important aspect in bank-run episodes (e.g., Kelly and O Grada, 2000; Starr and Yilmaz, 2007; Iyer and Puri, 2012). More specifically, depositors may or may not observe the actions of other depositors, depending on their position in line and the information structure in which depositors are set. Information about what is observed determines the degree of strategic uncertainty. This information and the position in line are revealed to depositors before they are asked to decide in period $t=1$. We present the sequence of events of our model in Figure 1.

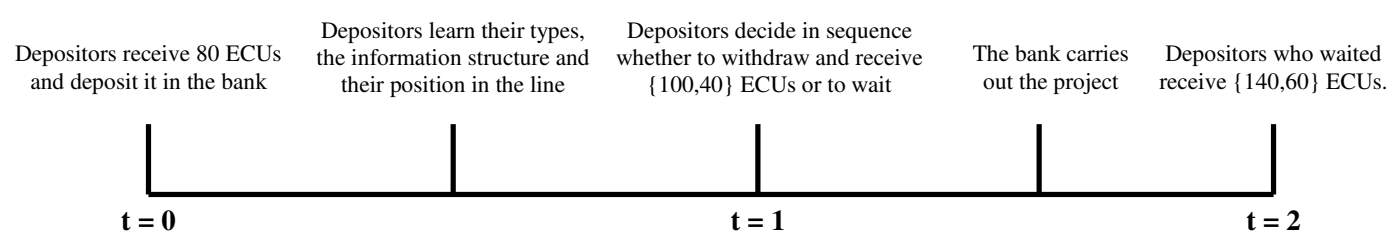

Figure 1: Timeline for the sequence of events.

As noted above, the available information about previous decisions depends on the information structure. In each of the information structures, the existence of a link $i j$ for $i, j \in\{1,2,3\}, i<j$ implies that depositor $j$ observes depositor $i$ and that depositor $i$ knows that depositor $j$ will observe her. For instance, in networks with the link 12 (i.e., $(12,23,13),(12,23)$, $(12,13)$, and $(12))$ depositor 1 chooses based on the knowledge that depositor 2 will observe her action and that depositor 2 chooses after observing depositor 1's action. In our setup with three depositors, there are 8 possible information structures: $(12,23,13),(12,23),(12,13),(13,23),(12),(13)$, $(23)$ and $(\emptyset)$, where $(\emptyset)$ represents the empty network, which has no links at 
all, whereas the structure $(12,23,13)$ contains all possible links and is called the complete network. ${ }^{8}$

At the beginning of each round we hold two raffles. One raffle is used to assign subjects a position in the sequence of decisions $(i=1,2,3)$ and the other is used to assign the paired participants to one of the 8 information structures. In our experiment, the information is always local; thus, if $(12,23)$ is randomly selected in one of the rounds, with patient depositors being randomly set in positions 1 and 3, then depositor 1 knows that depositor 2 (depositor 3) will (not) observe her decision. Depositor 1, however, does not know whether depositor 3 will observe the choice of depositor 2 . In that regard, from depositor 1's perspective, she may be either in the network $(12,23)$ or in $(12,13,23)$. In our design, both possibilities are equally likely, and we informed the participants of this fact. Along these lines, if the structure $(12,23)$ is randomly selected, then depositor 3 chooses after observing only the choice of depositor 2 , but she has no information about whether depositor 2 observes depositor 1. Notably, in some rounds of the experiment depositor 3 chose after knowing the actions of depositor 1 and 2 , whereas in other rounds she had no information at all or was informed about the decision of only one of the previous depositors. ${ }^{9}$

As previously noted, one of the depositors always withdraws, which substantially increases the degree of strategic uncertainty. More precisely, in a setup in which depositor 3 observes a withdrawal, she does not know whether this action is a result of the impatient depositor (i.e., the computer) or a patient depositor (i.e., the other subject in the lab) who chose to withdraw. Similarly, in a context with no observations, depositor 3 decides in the presence of strategic uncertainty, not knowing what the other subject in the lab has chosen to do.

In both sessions, the participants were divided into three matching groups of 10. Participants within the same matching group were randomly matched

\footnotetext{
${ }^{8}$ We attempt to study the depositor's behavior in all possible information structures, not only in simultaneous and completely sequential decisions (e.g., Schotter and Yorulmazer, 2009; Kiss et al. 2012). In our setup, the empty network can be interpreted as a simultaneous-move game in which depositors have no information about other depositors' actions, as in Diamond and Dybvig (1983). The only difference is that positions are known in our setup in contrast to their study. The complete network represents a fully sequential setup in which depositors observe all predecessors' actions.

${ }^{9}$ To see how the different information structures affect depositors' decisions, see Kiss et al. (2014a).
} 
in pairs at the beginning of each round, and participants from different matching groups never interacted with one other throughout the session. The subjects received information about what happened in their bank (the number of withdrawals and their own payoffs) before being rematched.

Each session lasted approximately 90 minutes, and the participants received 15 euros on average, including the show-up fee of 3 euros. For the payment, we used a random lottery incentive procedure in which one choice (i.e., one of the rounds) was randomly paid at the end of the experiment, with ECUs being transformed into euros using the exchange rate in which $10 \mathrm{ECUs}=1$ euro.

\subsection{Predictions}

Next, we posit a straightforward prediction of our model that we seek to test with our behavioral data. ${ }^{10}$

Proposition. Depositor 3 has a dominant strategy and should always wait if she is patient, regardless of what she observes (if anything).

Proof. Because one of the depositors is forced to withdraw, a patient depositor's decision in position 3 can be preceded by two withdrawals, or by one waiting decision and one withdrawal. It is straightforward to show that waiting is a dominant strategy for any of these two possible histories of decisions, given the payoffs. We show next that the decisions observed by depositor 3 may determine how difficult it is to identify this dominant strategy. If depositor 3 observes a waiting, or a waiting and a withdrawal, then choosing to wait enables her to receive 140 ECUs, whereas withdrawal would yield 100 ECUs. Thus, it is clear that depositor 3 should wait. Similarly, upon observing two withdrawals, depositor 3 knows that the other patient depositor decided to withdraw; thus, the optimal decision is to wait and earn 60 ECUs (instead of earning the 40 ECUs that a withdrawal would yield). However, if depositor 3 observes a withdrawal, then she cannot infer whether it was from the other patient depositor or the impatient depositor. In either case, it is better for depositor 3 to wait. Note that waiting (withdrawing) after two withdrawals yields 60 ECUs (40 ECUs), whereas waiting (withdrawing) after a waiting and a withdrawal yields 140 ECUs (100 ECUs). Decision making is more difficult because she must consider two potential scenarios. Depositor 3 should apply the same reasoning if she observes nothing (i.e., depositor 3 should think that for any possible history of decisions it is preferable for her to wait).

\footnotetext{
${ }^{10}$ This is part of the theoretical model in Kiss et al. (2014a)
} 
Our objective is to study the extent to which depositor 3 follows her dominant strategy and waits. By the same token, we want to investigate how the observability of actions affects her decision. More precisely, the proof of our proposition - although simple - highlights the potential role of strategic uncertainty. There is no strategic uncertainty if depositor 3 observes i) a waiting decision, ii) a waiting decision and a withdrawal, or iii) two withdrawals, as the observability of actions in these cases allows depositor 3 to fully identify the action of the other patient depositor. In that context, choosing the dominant strategy should be easy for depositor 3 , as this decision is based on simply comparing the payoffs of waiting (140 ECUs) and withdrawing (100 ECUs). Although waiting is also a dominant strategy in the context of strategic uncertainty (i.e., when depositor 3 observes i) nothing or ii) only a withdrawal) the computation of payoffs is less straightforward, as the depositor needs to figure out that waiting is the optimal decision for any possible history of decisions that is compatible with what is observed. In addition, the depositor does not know whether waiting (withdrawing) will yield 60 or 140 ECUs (40 or 100 ECUs).

Next we summarize our research questions:

1. Does depositor 3 follow her dominant strategy and wait, regardless of her observations?

2. Is depositor 3 more likely to wait when there is no strategic uncertainty (i.e., when the other patient depositor's action is observed) compared with the situation involving strategic uncertainty (because no previous choice or only a withdrawal is observed)?

3. What is the predictive power of the Cognitive Reflection Test (CRT) in identifying the dominant strategy? Do cognitive abilities predict behavior in a context with (without) strategic uncertainty?

\subsection{Debriefing questionnaire}

At the end of the experiment, the participants completed a questionnaire that was used to collect additional information on gender, the degree of risk aversion and cognitive abilities.

We elicited risk attitudes using the investment decision in Gneezy and Potters (1997). Each participant hypothetically received 10 euros and was 
asked to choose how much of this amount, $x$, she wanted to invest in a risky option and how much she wished to keep. The amount invested yielded a dividend equal to $2.5 x$ with $1 / 2$ probability, being lost otherwise. The money not invested in the risky option $(10-x)$ was kept by the participant. In this situation, the expected value of investing is positive and increasing in the amount invested; therefore a risk-neutral (or risk-loving) participant should invest 10 euros, whereas a risk-averse participant will invest less. The amount that is not invested in the risky asset is a natural measure of risk aversion.

The questionnaire also contained the CRT in Frederick (2005).

\section{Results}

We have a total of 60 subjects making decisions for 15 rounds (i.e., 900 decisions). Because positions are randomly determined at the beginning of each round, we have 299 decisions that correspond to depositor 1, 289 decisions that correspond to depositor 2, and 312 decisions that correspond to depositor 3. We shall focus our analysis on the later decisions, as depositor 3 has a dominant strategy.

Table 1 shows the basic descriptive statistics of the sample. The sociodemographics are presented in panel $i$ ). This includes information about risk aversion (Gneezy and Potters, 1997), the participants' gender, and the CRT score. As for the behavioral data in panel $i i$ ), we report the frequency of choices that correspond to depositor 3 withdrawing. To assess the importance of strategic uncertainty, we define a dummy variable $\left(I_{S U}\right)$ that takes the value of 1 when there is strategic uncertainty in position 3 (i.e., $I_{S U}$ takes the value of 1 when either nothing or only a withdrawal is observed). To show the importance of the CRT, we separately report the frequency of withdrawal for participants whose CRT scores equal to or are larger than 0, separately (see Brañas-Garza et al. 2012).

The behavioral data reveal a withdrawal rate of $10 \%$, indicating that the depositors in position 3 usually recognize the dominant strategy and tend to wait. Panel $i$ ) also reveals the role of strategic uncertainty. When depositor 3 makes her decision in the absence of strategic uncertainty, $4 \%$ of the decisions correspond to withdrawal (17\% if there is strategic uncertainty). The relationship between cognitive abilities and the withdrawal 
Table 1: Summary of the data

Mean Std.Dev. Min. Max.

\begin{tabular}{|c|c|c|c|c|}
\hline \multicolumn{5}{|l|}{ i) Socio-demographics } \\
\hline Risk aversion & 5.58 & 1.80 & 0 & 10 \\
\hline Gender (=1 if female) & 0.50 & 0.50 & 0 & 1 \\
\hline Cognitive abilities (CRT) & 0.57 & 0.98 & 0 & 3 \\
\hline \multicolumn{5}{|l|}{ ii) Behavioral data } \\
\hline Withdrawal rate & 0.10 & 0.31 & 0 & 1 \\
\hline Withdrawal rate $\left(I_{S U}=0\right)$ & 0.04 & 0.19 & 0 & 1 \\
\hline Withdrawal rate $\left(I_{S U}=1\right)$ & 0.17 & 0.38 & 0 & 1 \\
\hline Withdrawal rate $(\mathrm{CRT}=0)$ & 0.12 & 0.33 & 0 & 1 \\
\hline Withdrawal rate $(\mathrm{CRT}>0)$ & 0.07 & 0.26 & 0 & 1 \\
\hline
\end{tabular}

decision is also worth mentioning. The frequency of withdrawal for participants with CRT $=0$ is almost twice as high as for participants with CRT $>0 .{ }^{11}$ These findings point out the importance of strategic uncertainty and cognitive abilities for withdrawal decisions (e.g., participants with higher cognitive abilities recognize the dominant strategy more easily). One interesting question to be addressed concerns the interaction between these two variables. $^{12}$

\footnotetext{
${ }^{11}$ Grimm and Mengel (2012) use a different split and assign participants with a CRT score equal to 3 to one group (reflective participants) and assign the other participants to another group. When we group the data using these categories we observe that reflective participants $(\mathrm{CRT}=3)$ never withdraw, whereas those with CRT $<3$ do withdraw (withdrawal rate of $11 \%$ ).

${ }^{12}$ Although we consider that strategic uncertainty and cognitive abilities are the leading explanations for suboptimal behavior, one may argue that depositors rush to withdraw their money so as to behave according to what they have observed; i.e., depositor 3 may have a preference for conformity (Bikhchandani et al. 1998). If this preference were held, then depositor 3 would be more likely to withdraw after observing two withdrawals, compared with the case in which only one withdrawal is observed. Our data suggest that conformity cannot explain departures from the equilibrium prediction as depositor 3 never withdraws upon observing two withdrawals, with a withdrawal rate of approximately $17 \%$
} 
To provide some evidence in that dimension, we perform an econometric analysis. We estimate a logit model in which the dependent variable is the probability that depositor 3 withdraws. Because the participants are asked to make decisions during 15 rounds, we follow Garratt and Keister (2009) in using History as a control variable. In our case, History is defined as the share of previous rounds in which the participant observed the other patient depositor withdrawing. We control for the socio-demographics presented in Table 1: risk, gender, and cognitive abilities (i.e., the dummy variable $I_{C R T}$ equals 1 if CRT $>0$, and 0 otherwise). We also include a dummy variable to account for strategic uncertainty $\left(I_{S U}\right)$. The magnitude of the interaction effect of cognitive abilities and strategic uncertainty is estimated according to Ai and Norton (2003). The estimated standard errors in parentheses take into account matching group clustering and are corrected using bias reduced linearization (Bell and McCaffrey, 2002). ${ }^{13}$ The analysis is summarized in Table 2 .

Our estimates suggest that cognitive abilities affect the depositors' behavior; however there is an interesting link between their predictive power and strategic uncertainty, as indicated by the first regression, in which both strategic uncertainty and its interaction with CRT are significant. To disentangle the effect of strategic uncertainty and the CRT, we report the marginal effects for withdrawal decisions with and without strategic uncertainty in the last two columns. The importance of strategic uncertainty is clear from the observed probability, which is estimated to be close to $0 \%$ when there is no strategic uncertainty (versus approximately $15 \%$ when there is strategic uncertainty). The effect of the CRT is also evident in Table 2. When decisions are made in a context without strategic uncertainty, the dominant strategy is easy to identify and the CRT has no predictive power $(\mathrm{p}$-value $=0.361)$. However, the CRT does predict withdrawal decisions in the presence of strategic uncertainty $(\mathrm{p}$-value $=0.003)$. The participants

when only a withdrawal is observed.

${ }^{13}$ Our results are invariant if we do not perform these corrections, although we should be careful in interpreting the magnitude of the interaction term, which does not equal the marginal effect of the interaction term in logit models (Ai and Norton, 2003). In addition, not accounting for the BRL implies that the standard errors would be biased and we would be more likely to reject the null hypothesis than our p-values would suggest (see Angrist and Pischke, 2008). Our results are also robust if we use the score in the CRT rather than the dummy $I_{C R T}$ as the independent variable (see Table 3 in Appendix $\mathrm{B}$ for further details). 
Table 2: Marginal effects for withdrawal decisions in position 3 after logit estimation.

\begin{tabular}{|c|c|c|c|}
\hline & $\begin{array}{c}\text { Pooled } \\
\text { Data }\end{array}$ & $\begin{array}{l}\text { No Strategic } \\
\text { Uncertainty }\end{array}$ & $\begin{array}{c}\text { Strategic } \\
\text { Uncertainty }\end{array}$ \\
\hline \multirow[t]{2}{*}{ History } & -0.178 & -0.048 & -0.229 \\
\hline & $(0.133)$ & $(0.044)$ & $(0.205)$ \\
\hline \multirow[t]{2}{*}{ Risk aversion } & -0.002 & 0.0002 & -0.009 \\
\hline & $(0.006)$ & $(0.001)$ & $(0.014)$ \\
\hline \multirow[t]{2}{*}{ Gender ( $=1$ if female) } & 0.009 & 0.011 & -0.040 \\
\hline & $(0.033)$ & $(0.013)$ & $(0.059)$ \\
\hline \multirow[t]{2}{*}{ Cognitive abilities $\left(I_{C R T}\right)$} & 0.126 & 0.032 & $-0.154^{* *}$ \\
\hline & $(0.033)$ & $(0.035)$ & $(0.051)$ \\
\hline \multirow[t]{2}{*}{ Strategic uncert. $\left(I_{S U}\right)$} & $0.198^{* *}$ & & \\
\hline & $(0.048)$ & & \\
\hline \multirow{2}{*}{$I_{C R T} \times I_{S U}$} & $-0.143^{* *}$ & & \\
\hline & $(0.034)$ & & \\
\hline Obs. Probability & 0.063 & 0.004 & 0.149 \\
\hline Wald test & $3.310^{5 * *}$ & $39.722^{* *}$ & $7.598^{* *}$ \\
\hline Observations & 312 & 154 & 158 \\
\hline \multicolumn{4}{|c|}{$\begin{array}{l}\text { Notes. The set of independent variables include the share of previous rounds in which the participant } \\
\text { observed the other patient depositor withdrawing (History), a proxy for risk aversion as measured with the } \\
\text { investment decision in Gneezy and Potters (1997), a dummy variable for the participant's gender, a dummy } \\
\text { variable } I_{C R T} \text { for the score in the Cognitive Reflection Test (CRT) in Frederick (2005), and a dummy } \\
\text { variable } I_{S U} \text { for the possibility of choosing in a context with strategic uncertainty. The interaction term of } \\
\text { the dummy variables is corrected using Ai and Norton (2003). The estimated standard errors in parentheses } \\
\text { take into account matching group clustering and are corrected using the Bias Reduced Linearization (Bell } \\
\text { and McCaffrey, 2002). }{ }^{* *} \text { p p }<0.01,{ }^{*} \text { p }<0.00\end{array}$} \\
\hline
\end{tabular}


with positive scores on the CRT are $15 \%$ less likely to withdraw.

Finally, we assess the issue of the consistency of choices, which is frequently related to cognitive abilities in the context of risk decisions (Eckel, 1999), time decisions (Burks et al. 2009), and social preferences (Chen et al. 2013). Because decisions are made both with and without strategic uncertainty, we can compute the difference between the frequency of withdrawing in position 3 for each subject when there is strategic uncertainty and when there is not. The more these frequencies differ, the more the subject tends to react to strategic uncertainty (i.e., decisions are less consistent). The Spearman's correlation coefficient suggests that our measure of consistency is negatively correlated with the $\operatorname{CRT}(\rho=-0.271, p-$ value $=0.059)$; i.e., subjects with higher levels of cognitive abilities are less likely to vary their decisions in the presence of strategic uncertainty.

\section{Concluding Remarks}

This paper is a contribution to the stream of research that investigates the predictive power of cognitive abilities in decision making. We examine the effect of the CRT on withdrawal decisions in a bank-run situation, as depositors' decisions have been frequently associated with irrational behavior. Our game relies on the seminal model by Diamond and Dybvig (1983), which we extend to allow for the observability of actions. Interestingly, the last depositor in the sequence of decisions has a dominant strategy in our setup and should always keep the money deposited if the depositor is rational. One characteristic feature of our design is that depositors may observe previous choices, which may affect the degree of strategic uncertainty.

Our data show that the majority of the participants in our bank-run game follow the dominant strategy and tend to wait, with low withdrawal rates. The observability of actions, however, is an important element, as withdrawals occur more frequently when there is strategic uncertainty. In that context, the CRT has predictive power, and participants with stronger abilities tend to identify the dominant strategy more easily. Interestingly, the CRT does not predict behavior when there is no strategic uncertainty.

Although we cast our model in a banking environment, run-like phenomena also occur in other institutions and markets in which investors can easily withdraw funds or cease to roll over their investments. Our analysis 
may also be valid in such settings. For instance, Northern Rock, the English bank, was first run not by depositors, but by large creditors who provided short-term funding to the bank and did not renew it. Run-like episodes also occurred in money market, hedge and pension funds (Baba, McCauley and Ramaswamy, 2009); in the repo market (Gorton and Metrick, 2012); and even in bank lending (Ivashina and Scharfstein, 2010). In all these situations, depositors or investors may have a dominant strategy of waiting and not acting impulsively, but uncertainty about the decisions of other depositors can lead to panicking behavior. This effect is relevant, for instance, to the optimal design of deposit insurance, which should account for situations in which some depositors may run even if the insurance scheme protects them. Our results suggest that more information about previous decisions helps to reduce the probability of suboptimal decisions, and this finding may be relevant for policymakers.

\section{Acknowledgements}

We benefited from comments and suggestions provided by the two editors in charge of the special issue, Pablo Brañas-Garza and John Smith, and two anonymous referees, who really helped to improve the quality of our manuscript. We also thank financial support from the Spanish Ministry of Education under the projects ECO2011-25349 (Hubert Janos Kiss), ECO2011-29230 (Ismael Rodriguez-Lara), ECO2010-19830 (Alfonso Rosa García), as well as from the Hungarian Scientific Research Fund (OTKA) under the project PD 105934 (Hubert Janos Kiss). Hubert Janos Kiss is a research fellow in the Momentum (LD-004/2010) Game Theory Research Group at MTA KRTK. Ismael Rodriguez-Lara is a research fellow at LUISS Guido Carli University, Rome. The usual disclaimers apply. 


\section{References}

[1] Agarwal, S., Mazumder, B., 2013. Cognitive abilities and household financial decision making. American Economic Journal: Applied Economics, 5(1), 193207.

[2] Ai, A., Norton, E.C., 2003. Interaction terms in logit and probit models. Economics Letters, 80, 123-129.

[3] Allred, S., Duffy, S., Smith, J., 2014. Cognitive load and strategic sophistication, MPRA Paper No. 57662

[4] Andersson, O., Tyran, J. R., Wengström, E., Holm, H. J., 2013. Risk aversion relates to cognitive ability: Fact or fiction?, IFN Working Paper No. 964.

[5] Angrist, J. D., Pischke, J.-S., 2008. Nonstandard standard error issues, in: Mostly Harmless Econometrics: An Empiricists Companion. Princeton University Press.

[6] Baba, N., McCauley, R., and Ramaswamy, S., 2009. US dollar money market funds and non-US banks. BIS Quarterly Review, March.

[7] Ballinger, T. P., Hudson, E., Karkoviata, L., Wilcox, N. T., 2011. Saving behavior and cognitive abilities. Experimental Economics, 14(3), 349-374.

[8] Bayer, R., Renou, L., 2012. Logical abilities and behavior in strategic-form games. Working paper, University of Leicester.

[9] Benito-Ostolaza, J. M., Hernández, P., Sanchis-Llopis, J. A., 2015. Are individuals with higher cognitive ability expected to play more strategically?, mimeo.

[10] Bell, R. M., McCaffrey, D. F., 2002. Bias reduction in standard errors for linear regression with multi-stage samples. Survey Methodology, 28(2), 169-182.

[11] Benjamin, D. J., Brown, S. A., Shapiro, J. M., 2013. Who is 'behavioral'? Cognitive ability and anomalous preferences. Journal of the European Economic Association, 11(6), 1231-1255.

[12] Bergman, O., Ellingsen, T., Johannesson, M., Svensson, C., 2010. Anchoring and cognitive ability. Economics Letters, 107, $66 ? 68$.

[13] Bertrand, M., Morse, A., 2011. Information Disclosure, Cognitive Biases, and Payday Borrowing. Journal of Finance 66 (6), 1865-93.

[14] Bikhchandani, S., Hirshleifer, D., Welch, I., 1998. Learning from the behavior of others: Conformity, fads, and informational cascades. The Journal of Economic Perspectives 12 (3), 151-170. 
[15] Brañas-Garza, P., Espinosa, M. P., Rey-Biel, P., 2011. Travelers' types. Journal of Economic Behavior and Organization, 78, 25-36.

[16] Brañas-Garza, P., García-Muñoz, T., González, R. H., 2012. Cognitive effort in the beauty contest game. Journal of Economic Behavior and Organization, $83(2), 254-260$.

[17] Brañas-Garza, P., Guillen, P., del Paso, R. L., 2008. Math skills and risk attitudes. Economics Letters, 99(2), 332-336.

[18] Bosch-Domènech, A., Brañas-Garza, P., Espín, A. M., 2014. Can exposure to prenatal sex hormones (2D: 4D) predict cognitive reflection?. Psychoneuroendocrinology, 43, 1-10.

[19] Burks, S. V., Carpenter, J. P., Goette, L., Rustichini, A., 2009. Cognitive skills affect economic preferences, strategic behavior, and job attachment. Proceedings of the National Academy of Sciences, 106(19), 7745-7750.

[20] Baghestanian, S., Frey, S., 2014. GO Figure: Analytic and Strategic Skills are Separable. SSRN Working Paper.

[21] Carpenter, J., Graham, M., Wolf, J., 2013. Cognitive Ability and Strategic Sophistication. Games and Economic Behavior 80(1), 115-130.

[22] Casari, M., Ham, J. C., Kagel, J. H., 2007. Selection bias, demographic effects, and ability effects in common value auction experiments. The American Economic Review, 1278-1304.

[23] Chen, C. C., Chiu, I. M., Smith, J., Yamada, T. 2013. Too smart to be selfish? Measures of cognitive ability, social preferences, and consistency. Journal of Economic Behavior and Organization, 90, 112?122

[24] Christelis, D., Jappelli, T., Padula, M., 2010. Cognitive abilities and portfolio choice. European Economic Review, 54(1), 18-38.

[25] Choi, J. J., Laibson, D., Madrian, B. C., 2011. $\$ 100$ bills on the sidewalk: Suboptimal investment in $401(\mathrm{k})$ plans. Review of Economics and Statistics, $93(3), 748-763$.

[26] Corgnet, B., Hernán-González, R., Kujal, P., Porter, D., 2014. The Effect of Earned Versus House Money on Price Bubble Formation in Experimental Asset Markets. Review of Finance, forthcoming, doi: 10.1093/rof/rfu03.

[27] Diamond, D.W., Dybvig, P.H., 1983. Bank runs, deposit insurance and liquidity. Journal of Political Economy 91, 401-419.

[28] Dohmen, T., Falk, A., Huffman, D., Sunde, U., 2010. Are Risk Aversion and Impatience Related to Cognitive Ability? American Economic Review, 100, 1238-1260. 
[29] Eckel, C., 1999. Commentary on "The effects of financial incentives in experiments: a review and capital-labor-production framework". Journal of Risk and Uncertainty 19, 47-48.

[30] Fischbacher, U., 2007. z-Tree: Zurich toolbox for readymade economic experiments. Experimental Economics 10, 171-178

[31] Frederick, S., 2005. Cognitive reflection and decision making. Journal of Economic perspectives 19(4), 25-42.

[32] Garratt, R., Keister, T., 2009. Bank runs as coordination failures: An experimental study. Journal of Economic Behavior and Organization 71, 300-317.

[33] Gerardi, K., Goette, L., Meier, S., 2013. Numerical ability predicts mortgage default. Proceedings of the National Academy of Sciences, 110(28), 1126711271.

[34] Gill, D., Prowse, V., 2014. Cognitive ability, character skills, and learning to play equilibrium: A level-k analysis. Working Paper, Cornell University.

[35] Gneezy, U., Potters, J., 1997. An experiment on risk taking and evaluation periods. The Quarterly Journal of Economics 112(2), 631-645.

[36] Gorton, G., and Metrick, A. (2012) Securitized banking and the run on repo. Journal of Financial Economics 104(3), 425-451.

[37] Grimm, V., Mengel, F., 2012. An experiment on learning in a multiple games environment. Journal of Economic Theory, 147(6), 2220-2259.

[38] Grinblatt, M., Keloharju, M., Linnainmaa, J. T., 2012. IQ, trading behavior, and performance. Journal of Financial Economics, 104(2), 339-362.

[39] Gu, C., 2011. Herding and bank runs. Journal of Economic Theory 146, 163188.

[40] Insler, M., Compton, J., Schmitt, P., 2015. The investment decisions of young adults under relaxed borrowing constraints, mimeo.

[41] Ivashina, V., and Scharfstein, D. (2010) Bank lending during the financial crisis of 2008. Journal of Financial Economics 97(3), 319-338.

[42] Iyer, R., Puri, M., 2012. Understanding bank runs: The Importance of depositor-bank relationships and networks. American Economic Review 102, 1414-1445.

[43] Jones, G., 2008. Are smarter groups more cooperative? Evidence from prisoner's dilemma experiments. Journal of Economic Behavior and Organization, 68, 489-497.

[44] Jones, M. T., 2014. Strategic Complexity and Cooperation: An Experimental Study. Journal of Economic Behavior and Organization, 106, 352-366. 
[45] Kahneman, D., 2011. Thinking, Fast and Slow. Edited by: Farrar, Strauss and Giroux, New York.

[46] Kelly, M., O Grada, C., 2000. Market contagion: Evidence from the panics of 1854 and 1857. American Economic Review 90, 1110-1124.

[47] Kinateder, M., Kiss, H. J., 2014. Sequential decisions in the Diamond-Dybvig banking model. Journal of Financial Stability 15, 149-160

[48] Kiss, H. J., Rodriguez-Lara, I., Rosa-Garcia, A., 2012. On the effects of observability and deposit insurance on bank runs: An experimental study. Journal of Money, Credit and Banking 44, 1651-1665.

[49] Kiss, H. J., Rodriguez-Lara, I., Rosa-Garcia, A., 2014a. Do social networks prevent or promote bank buns? Journal of Economic Behavior and Organization 101, 87-99.

[50] Kiss, H. J., Rodriguez-Lara, I., Rosa-Garcia, A., 2014b. Do women panic more than men? An experimental analysis of financial decisions. Journal of Behavioral and Experimental Economics 52, 40-51.

[51] Korniotis, G., Kumar, A., 2010. Cognitive Abilities and Financial Decisions. In H. Kent Baker and John Nofsinger (eds.) Behavioral Finance, Hoboken, NJ: John Wiley \& Sons, Inc.

[52] Korniotis, G. M., Kumar, A., 2013. Do portfolio distortions reflect superior information or psychological biases?. Journal of Financial and Quantitative Analysis, 48(01), 1-45.

[53] Oechssler, J., Roider, A., Schmitz, P. W., 2009. Cognitive abilities and behavioral biases. Journal of Economic Behavior and Organization, 72, 147-152.

[54] Rydval, O., Ortmann, A., Ostatnicky, M., 2009. Three very simple games and what it takes to solve them. Journal of Economic Behavior and Organization $72,589-601$.

[55] Schotter, A., Yorulmazer, T., 2009. On the dynamics and severity of bank runs: An experimental study. Journal of Financial Intermediation 18, 217-241.

[56] Starr, M.A., Yilmaz, R., 2007. Bank runs in emerging-market economies: Evidence from Turkey's special finance houses. Southern Economic Journal 73, 1112-1132.

[57] Toplak, M. E., West, R. F., Stanovich, K. E., 2011. The cognitive reflection test as a predictor of performance on heuristics-and-biases tasks. Memory and Cognition, 39(7), 1275-1289.

[58] Van Rooij, M. C., Lusardi, A., Alessie, R. J., 2011. Financial literacy and retirement planning in the Netherlands. Journal of Economic Psychology, 32(4), 593-608. 


\section{Appendix A: Instructions ${ }^{14}$}

\section{Welcome to the experiment!}

This experiment aims to study decision making; we are not interested in your particular choices but are focusing on the average behavior of individuals. Therefore, during the experiment, you will be treated anonymously. Neither the experimenters nor the people in this room will ever know your particular choices.

You will find the instructions on the computer screen explaining how the experiment will unfold. The instructions are the same for all participants in the laboratory and will be read aloud by the experimenters. It is important for you to understand the experiment before starting, as the money that you will earn will depend on your choices. You also have a copy of the instructions on your table.

Should you have any problem during the experiment, please raise your hand and remember that you are not allowed to speak with anyone except the experimenter.

\section{Number of rounds}

This experiment has 18 rounds in total. The first 3 rounds are intended for you to become familiar with the software. The remaining 15 rounds will be used to determine your final payoff, so please be sure that you understand the experiment before starting the 4th round. This understanding will help you to earn more money.

\section{Deposits}

At the beginning of each round, you will be provided a certain amount of money (80 ECUs) to be deposited in a bank. The bank in which you will invest your money will be formed by 3 depositors: one of them is you, one is someone else in this room and the third depositor is simulated by the computer. Therefore, the bank in which you deposit your money will have 240 ECUs per round in total.

\section{Decisions and earnings}

In principle, your decision involves choosing whether to withdraw your money from the common bank in the first period or to wait until the second period, considering that your earnings will depend not only on your choice but also on other depositors' choices. It is important that you know that the computer will always withdraw its money; thus, your earnings in each round will depend only on your choice and the choice of the other depositor in this room.

\footnotetext{
${ }^{14}$ Instructions are originally in Spanish.
} 
Specifically, if you both wait until the second period to withdraw your money, you will receive 140 ECUs, corresponding to your initial investment (80 ECUs) plus interest generated during the first period (during which you decided to wait).

If only one of you withdraws the money, then the one who withdraws receives 100 ECUs (which is the same amount that the computer will take in this case). The depositor who waits will receive 60 ECUs (corresponding to the remaining amount in the bank after two withdrawals - 40 ECUs plus an additional 20 ECUs of interest).

Finally, it might be the case that both of you withdraw your money in the first period. As a result, your earnings will depend on the available amount of money in the bank and your position in line. Therefore, if you are at Position 1 or Position 2 in line and decide to withdraw, then you will receive 100 ECUs; however, if you are the last one in line (Position 3), then only 40 ECUs remain in the bank, and you will receive that amount.

Therefore, your payoffs can be summarized in the following table:

\begin{tabular}{|c|c|c|c|}
\cline { 3 - 4 } \multicolumn{2}{c|}{} & \multicolumn{2}{c|}{$\begin{array}{c}\text { In you decide to wait in the first year and } \\
\text { withdraw in the second, the... }\end{array}$} \\
\hline $\begin{array}{c}\text { Number of previous } \\
\text { withdrawals }\end{array}$ & $\begin{array}{c}\text { If you withdraw the } \\
\text { first year }\end{array}$ & $\begin{array}{c}\text { you both wait and } \\
\text { only the computer } \\
\text { withdraws }\end{array}$ & $\begin{array}{c}\text { If, in addition to the } \\
\text { computer, the other } \\
\text { depositor withdraws }\end{array}$ \\
\hline 0 & 100 & 140 & 60 \\
\hline 1 & 100 & 140 & 60 \\
\hline 2 & 40 & Not applicable & 60 \\
\hline
\end{tabular}

Please remember that the depositor simulated by the computer will always withdraw its money in the first period.

Before beginning, please consider the following:

1. The person with whom you are linked will change in every round. As a result, do not assume that you are going to play the entire game with the same person.

2. You will always know your position in line, but this position might change in each round. In particular, you have the same probabilities of being in Position 1, Position 2 or Position 3. The same is true for the computer's position.

3. In each round, you will have different information about what the other depositors at your bank have chosen. Therefore, in some cases, you will know what has happened before you arrived at the bank (the number of wait and withdrawal decisions), but in other cases, you will not have this information. When you make your choice, you will also know whether someone else will observe your action. It 
may be in your interest to consider this information when making your decision. This information will appear on the left-hand side of the computer screen.

E.g.: You are in Position 1. The depositors in Position 2 and Position 3 will observe your action.

E.g.: You are in Position 2. The depositor in Position 1 has chosen to wait. The depositor in Position 3 will not observe your action.

On the right-hand side of your screen, a small graph shows with whom you are linked (that is, the person whom you observe and who will observe you). If there is no link between two depositors, then the text on the screen indicates that the depositor who decides later cannot observe the action of the other depositor. The symbol "?" indicates that you do not know whether the other two depositors are linked.

\section{Final payoff}

When the experiment ends, we randomly choose one of the 15 rounds and pay you according to the earnings from that round. We convert your earnings in that round at a rate $10 \mathrm{ECUs}=1$ euro.

We will now start with the first three rounds. At the end of these three rounds, you can ask any questions to ensure that you understand the procedure. If you have any doubts after the first three rounds, please raise your hand and remain silent. You will be attended by the experimenters as soon as possible. Talking is not allowed during this experiment. 


\section{Appendix B: Econometric results}

This appendix replicates the econometric results of Section 4 for the case in which the CRT score (rather than the dummy variable $I_{C R T}$ ) is used as the independent variable.

Table 3: Marginal effects for withdrawal decisions in position 3 after logit regression

\begin{tabular}{|c|c|c|c|}
\hline & $\begin{array}{l}\text { Pooled } \\
\text { Data }\end{array}$ & $\begin{array}{l}\text { No Strategic } \\
\text { Uncertainty }\end{array}$ & $\begin{array}{c}\text { Strategic } \\
\text { Uncertainty }\end{array}$ \\
\hline \multirow[t]{2}{*}{ History } & -0.188 & -0.067 & -0.226 \\
\hline & $(0.127)$ & $(0.040)$ & $(0.188)$ \\
\hline \multirow[t]{2}{*}{ Risk aversion } & -0.004 & -0.0003 & -0.007 \\
\hline & $(0.004)$ & $(0.001)$ & $(0.012)$ \\
\hline \multirow[t]{2}{*}{ Women } & 0.001 & 0.008 & -0.036 \\
\hline & $(0.033)$ & $(0.014)$ & $(0.057)$ \\
\hline \multirow[t]{2}{*}{ CRT } & 0.069 & 0.016 & $-0.336^{* *}$ \\
\hline & $(0.034)$ & $(0.014)$ & $(0.120)$ \\
\hline \multirow[t]{2}{*}{ Str. Uncert. (SU) } & $-0.168^{* *}$ & & \\
\hline & $(0.041)$ & & \\
\hline \multirow{2}{*}{ CRT x SU } & $-0.278^{* *}$ & & \\
\hline & $(0.104)$ & & \\
\hline Obs. Probability & 0.066 & 0.008 & 0.140 \\
\hline Wald test & $6.1010^{3 * *}$ & $60.75^{* *}$ & $9.54^{* *}$ \\
\hline Observations & 312 & 154 & 158 \\
\hline \multicolumn{4}{|c|}{$\begin{array}{l}\text { Notes. The set of independent variables include the share of previous rounds in which the participant } \\
\text { observed the other patient depositor withdrawing (History), a proxy for risk aversion as measured with } \\
\text { the investment decision in Geeezy and Potters (1997), a dummy variable for the participant's gender, the } \\
\text { score in the Cognitive Reflection Test (CRT) in Frederick (2005), and a dummy variable for the possibility } \\
\text { of choosing in a context with strategic uncertainty (SU). The interaction term of the dummy variables is } \\
\text { corrected using Ai and Norton (2003). The estimated standard errors in parentheses take into account } \\
\text { matching group clustering and are corrected using the Bias Reduced Linearization (Bell and MCCaffrey, } \\
\text { 2002). }{ }^{* *} \mathrm{p}<0.01,{ }^{*} \text { p }<0.05\end{array}$} \\
\hline
\end{tabular}

